Article

\title{
Numerical Study of Heat Transfer Enhancement of Internal Flow Using Double-Sided Delta-Winglet Tape Insert
}

\author{
Agung Tri Wijayanta ${ }^{1, *}$, Muhammad Aziz ${ }^{2}\left(\mathbb{D}\right.$, Keishi Kariya ${ }^{3}$ and Akio Miyara ${ }^{3}(\mathbb{D}$ \\ 1 Department of Mechanical Engineering, Universitas Sebelas Maret, Kampus UNS Kentingan, \\ Jl. Ir. Sutami 36A Kentingan, Surakarta 57126, Indonesia \\ 2 Institute of Innovative Research, Tokyo Institute of Technology, 2-12-1 Ookayama, Meguro-ku, \\ Tokyo 152-8550, Japan; aziz.m.aa@m.titech.ac.jp \\ 3 Department of Mechanical Engineering, Graduate School of Science and Engineering, Saga University, \\ 1 Honjomachi, Saga-shi 840-8502, Japan; kariya@me.saga-u.ac.jp (K.K.); miyara@me.saga-u.ac.jp (A.M.) \\ * Correspondence: agungtw@uns.ac.id; Tel.: +62-271-632-163
}

Received: 31 October 2018; Accepted: 13 November 2018; Published: 15 November 2018

\begin{abstract}
A numerical study was performed to investigate the thermal performance characteristics of an enhanced tube heat exchanger fitted with punched delta-winglet vortex generators. Computational fluid dynamics modeling was applied using the $k-\varepsilon$ renormalized group turbulence model. Benchmarking was performed using the results of the experimental study for a similar geometry. Attack angles of $30^{\circ}, 50^{\circ}$, and $70^{\circ}$ were used to investigate the heat transfer and pressure drop characteristics of the enhanced tube. Flow conditions were considered in the turbulent region in the Reynolds number range of 9100 to 17,400. A smooth tube was employed for evaluating the increment in the Nusselt number and the friction factor characteristics of the enhanced tube. The results show that the Nusselt number, friction factor, and thermal performance factor have a similar tendency. The presence of this insert offers a higher thermal performance factor as compared to that obtained with a plain tube. Vortex development in the flow structure aids in generating a vortex flow, which increases convective heat transfer. In addition, as the angle is varied, it is observed that the largest attack angle provides the highest thermal performance factor. The greatest increase in the Nusselt number and friction factor, respectively, was found to be approximately 3.7 and 10 times greater than those of a smooth tube. Through numerical simulations with the present simulation condition, it is revealed that the thermal performance factor approaches the value of 1.1. Moreover, the numerical and experimental values agree well although they tend to be different at high Reynolds number conditions. The numerical and experimental values both show similar trends in the Nusselt number, friction factor, and thermal performance factor.
\end{abstract}

Keywords: delta-winglet vortex generator; attack angle; thermal performance factor; turbulent flow

\section{Introduction}

The high performance requirements of heat exchange devices have resulted in the development of high performance heat exchangers. This has been followed by the consideration of the reduction in energy consumption and material used to achieve an economical cost. The numerous designs that have been reported are mainly used for heat-transfer enhancement to realize a high performance $[1,2]$. However, although these designs provide a high heat transfer rate, the requirements for the increase in pumping power cannot be neglected. A large amount of attention has been focused on lowering the pumping power to meet a desired performance under the design constraints. Experiments and simulations have been used to develop numerous heat transfer enhancement methods to achieve this 
condition. The potential method is changed into the passive method by using insert devices to lower the operating cost and reduce the energy consumption. This is evidenced by the fact that the passive method does not require external energy. This method could provide a high heat transfer rate by generating a secondary or vortex flow. This increases the turbulence intensity with a high temperature difference, such that a high convective heat transfer coefficient can be achieved, thus resulting in a high heat transfer rate.

Several studies have been conducted on such insertion. Several works are summarized hereafter. The passive heat transfer enhancement methods that are still used by the majority of researchers are swirl devices in the form of twisted tape [3-5], wire coil [6,7], helical screw [8,9], and vortex generators in the form of a winglet [10-12]. These were investigated under various parameters to determine the important factors that affect the performance of the heat exchanger. Torii and Yanagihara [13] studied the effect of the free-stream velocity, vortex generator height, and angle of attack on the heat transfer characteristics of the longitudinal vortex insert. They concluded that in the case of free stream velocity, an improvement in heat transfer occurs from the transition region to the turbulent regime. While an increase in the vortex height and angle of attack resulted in an increase in the heat transfer. The effect of the insertion inside the tube on the heat transfer enhancement was numerically investigated by Fu and Tseng [14]. They found that under a laminar flow condition, a tube with an insertion could enhance the heat transfer rate to two times greater than that of an empty tube. Chen et al. [15] explored the heat transfer enhancement in a finned oval tube heat exchanger fitted with punched delta-winglet pairs (DWPs). With respect to the arrangement of the DWPs, through a numerically study, they found that a change in the number of DWPs reveals a significant effect on the heat transfer enhancement. The high thermal performance could reach up to 1.04, especially for a finned oval tube heat exchanger with DWPs inline. The modeling of the heat transfer coefficients in a corrugated tube with a twisted tape insert was studied by Zimparov [16]. He compared the obtained results to the results of an experimental study. He found that the parameter that significantly affected the heat transfer coefficient in the case of the corrugated tube was the wall roughness. Within the range of the study, he confirmed that the difference between the numerical and experimental study results was less than $\pm 20 \%$.

A fin-and-oval-tube heat exchanger with longitudinal vortex generators (LVGs) was numerically studied by Chu et al. [17]. The optimization of the design was achieved by evaluating its performance on varying three parameters: The LVGs' arrangement, angle of attack, and tube-row number. They found that some combinations of these three parameters could enhance the heat transfer significantly. A downstream position with a low tube-row number and an angle of attack of $30^{\circ}$ results in a higher heat transfer performance. Hong et al. [18] presented a numerical simulation for the heat transfer and flow characteristics of converging-diverging tubes (CDTs) with a twin twisted tape insert. Within the range of the study, they considered the variation of the Reynolds number, pitch length, rib height, pitch ratio, gap distance, and tap number to be applied in their simulation. None of these was found to have an insignificant effect on the heat transfer and fluid flow characteristics. The important finding was that the compound CDTs offer a high thermal performance with a value greater than 1 for all the cases. The thermal-hydraulic performance of a perforated and typical helical fin in an air-to-water heat exchanger was studied both for a numerical and experimental investigation performed by Sheikholeslami and Ganji [19]. The parameters varied in their study were the Reynolds number, pitch ratio, and open area ratio. They stated that the important parameter was the open ratio, which gives a high thermal performance factor when the open-air ratio is high. The thermal performance and friction coefficient results show the influence of the attack angles of $15^{\circ}, 30^{\circ}$, and $45^{\circ}$ at various blockage ratios on the winglet vortex generator insert [20]. Piroozfam et al. [21] investigated three methods for enhancing the heat transfer in a heat exchanger. The methods were used while presenting an obstacle in the channel, modifying the flow with wavy channels (corrugated plate), and applying a sinusoidal flow. Each method affects the heat transfer enhancement of the system. The performance of their system was improved by $40-50 \%$. 
Although a considerable amount of research has been performed to study the effect of various parameters, an increase in the heat transfer could not be achieved alongside an increase in the friction factor (pressure drop). Therefore, there are further reasons for doing so relating the heat transfer enhancement. Numerical studies gained a great deal of attention owing to their advantage of clearly describing the physical phenomenon of the heat transfer enhancement. This could assist a design engineer of a heat exchange device to select an appropriate parameter. After publishing Ref. [22], we were motivated to extend the work to a numerical study of higher Reynolds numbers inside the tube in order to address the limitation of the experimental apparatus at higher mass flow rates. This is a reason why the present work has research novelty when compared to the previously published study. In the present work, we numerically investigate the thermal-hydraulic performance of the enhanced tube heat exchanger. Punched delta-winglet vortex generators (PDWVGs) are employed as the insert device, which could enhance the convective heat transfer. We verify the obtained results by comparing them with those of our previous experimental study [22] before comprehensively analyzing the thermal performance.

\section{Physical Model}

The geometries of the enhanced tube heat exchanger and PDWVGs are discussed individually. The heat exchanger, which is fabricated using aluminum, is a concentric tube heat exchanger that comprises an inner and outer tube. The parameter and dimension details of the heat exchanger are provided in Table 1.

Table 1. Parameters in the present numerical investigation.

\begin{tabular}{|c|c|c|}
\hline Parameter & Unit & Value \\
\hline $\begin{array}{ll} & \text { Inner tube } \\
\text { - } & \text { Inner diameter, } D_{i} \\
\text { - } & \text { Outer diameter, } D_{o} \\
\text { - } & \text { Length of the tube, } L_{i}\end{array}$ & $\begin{array}{l}\mathrm{mm} \\
\mathrm{mm} \\
\mathrm{mm}\end{array}$ & $\begin{array}{l}14.3 \\
15.8 \\
2110\end{array}$ \\
\hline $\begin{array}{l}\quad \text { Outer tube } \\
\text { - } \quad \text { Inner diameter, } d_{i} \\
\text { - } \quad \text { Outer diameter, } d_{o} \\
\text { - } \quad \text { Length of the tube, } L_{O}\end{array}$ & $\begin{array}{l}\mathrm{mm} \\
\mathrm{mm} \\
\mathrm{mm}\end{array}$ & $\begin{array}{l}24.3 \\
25.4 \\
2110\end{array}$ \\
\hline
\end{tabular}

Furthermore, the PDWVGs were manufactured using an aluminum strip of $0.7 \mathrm{~mm}$ thickness $(t), 12.6 \mathrm{~mm}$ width $(W)$, and $1200 \mathrm{~mm}$ length $(L)$ [22]. The winglet was fabricated at the center of the aluminum strip with a triangular shape and a constant height (c) of $8 \mathrm{~mm}$ and width $(w)$ of $4 \mathrm{~mm}$. It was designed in an upward and downward direction of the strip. The attack angle was formed owing to the difference in the reference line of the strip and the winglet body after punching this part guiding the flow along the strip insert. The attack angle was adjusted to $30^{\circ}, 50^{\circ}$, and $70^{\circ}$. The distance between each winglet (pitch, $P$ ) was fixed at $15 \mathrm{~mm}$ in the computations. The nomenclature of the PDWVGs is depicted in Figure 1.

To examine the thermal performance, including the heat transfer, fluid flow, and thermal performance characteristics, water was considered as the working fluid, i.e., hot water in the inner tube and cold water in the outer tube. The thermo-physical properties of the water were assumed to be temperature independent. Table 2 provides the thermo-physical properties of the water that were set as the inlet values for the computations. 


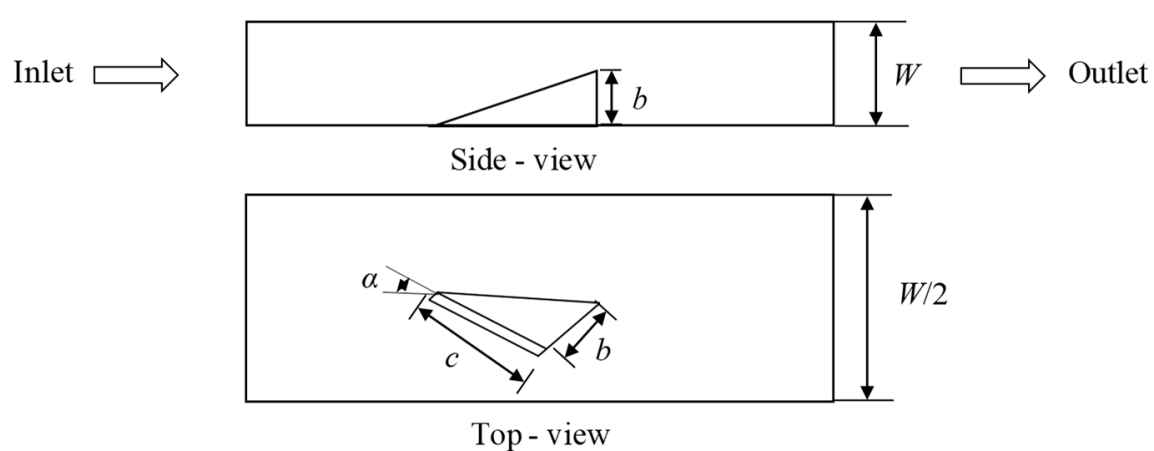

(a)
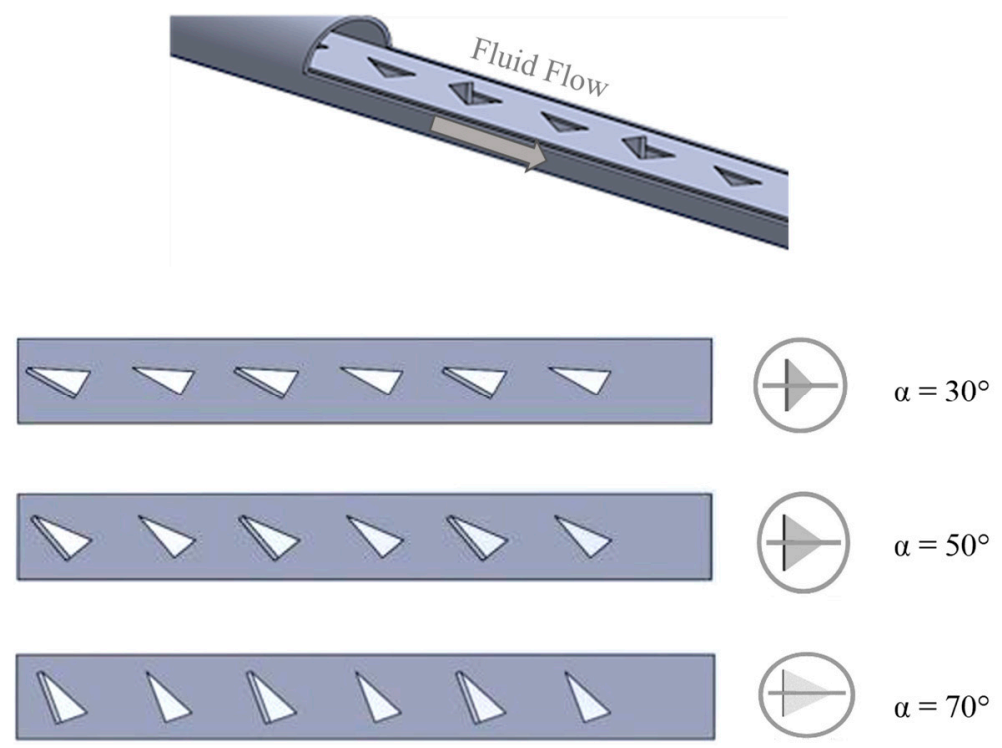

(b)

Figure 1. Geometrical definitions; (a) nomenclature of PDWVG; (b) PDWVGs with attack angle variation.

Table 2. Thermo-physical properties of the hot and cold water at the inlet.

\begin{tabular}{ccccccc}
\hline Fluid & Temperature $[\mathrm{K}]$ & $c_{\boldsymbol{p}}[\mathrm{kJ} / \mathbf{k g} \cdot \mathrm{K}]$ & $\rho\left[\mathrm{kg} / \mathrm{m}^{3}\right]$ & $\mu[\mathrm{kg} / \mathrm{m} \cdot \mathbf{s}]$ & $\boldsymbol{k}[\mathrm{W} / \mathrm{m} \cdot \mathbf{K}]$ & $\boldsymbol{P r}$ \\
\hline Hot water & 333.15 & 4.185 & 983.3 & $4.67\left(10^{-4}\right)$ & 0.654 & 2.99 \\
Cold water & 300.15 & 4.178 & 997 & $8.52\left(10^{-4}\right)$ & 0.613 & 5.81 \\
\hline
\end{tabular}

On considering the thermo-physical properties of the water and inner diameter of the inner tube, the Reynolds number can be defined as:

$$
\operatorname{Re}=\frac{\rho u D_{i}}{\mu}
$$

where $\rho$ is the water density; $u$ is the water velocity; and $\mu$ is the water dynamic viscosity. Based on the velocity variations, the Reynolds number was set to a value between 9100 and 17,400 and was increased in increments of 700. The heat transfer characteristic in terms of the Nusselt number is defined as:

$$
N u=\frac{h D_{i}}{k}
$$

where $h$ is the convective heat transfer coefficient, and $k$ is the thermal conductivity of the water. The fluid flow characteristics were examined using the friction factor, which is defined as follows: 


$$
f=\frac{\Delta P}{\left(\rho u^{2} / 2\right)\left(L / d_{i}\right)}
$$

The friction factor was calculated based on the pressure drop $(\Delta P)$ between the inlet and outlet of the tube.

\section{Numerical Technique}

To solve the numerical simulation, some assumptions are employed in the present study. The numerical simulation is assumed to be three-dimensional, the working fluid flow is assumed to be incompressible, and the flow is assumed to be in the turbulence region with constant properties. Three governing equations for continuity, momentum, and energy were employed to solve the computational problem. These equations are as follows:

Continuity equation:

$$
\frac{\partial}{\partial x_{i}}\left(\rho u_{i}\right)=0
$$

Momentum equation:

$$
\frac{\partial}{\partial x_{i}}\left(\rho u_{i} u_{k}\right)=\frac{\partial}{\partial x_{i}}\left(\mu \frac{\partial u_{k}}{\partial x_{i}}\right)-\frac{\partial p}{\partial x_{k}}
$$

Energy equation:

$$
\frac{\partial}{\partial x_{i}}\left(\rho u_{i} T\right)=\frac{\partial}{\partial x_{i}}\left(\frac{k}{c_{p}} \frac{\partial T}{\partial x_{i}}\right)
$$

where $\rho$ is the density of the fluid, $u$ is the mean component velocity, $p$ is the pressure, $\mu$ is the dynamic viscosity of the fluid, $c_{p}$ is the specific heat, $k$ is the thermal conductivity of the fluid, and $T$ is the temperature. The subscripts $i$ and $k$ indicate that the direction is towards $i$ and $k$.

The numerical simulation problem was considered to be three-dimensional, turbulent, and steady. The tube walls are considered to be adiabatic. A no-slip condition was set at the tube walls. Similar to the wall of the tubes, the boundary condition between the fluid and the insert devices was also considered as adiabatic. Fluent 15 was used to run the computational program [23]. Fluent works are based on the finite volume method. This method was also applied to solve Equations (4)-(6) while using the $k-\varepsilon$ renormalized group turbulence model. Moreover, to solve the momentum and energy equations, the standard-pressure and second-order upwind discretization was selected in the present work. The semi-implicit method for pressure linked equations (SIMPLE) algorithm was used to solve the pressure-velocity coupling. The tetrahedron-cell mesh configuration was used for the validation of the plain tube and delta-winglet tapes (DWTs). Regeneration of the mesh in plain tube and DWTs is given in Figure 2. Furthermore, the face sizing method was also used for the model in several areas.

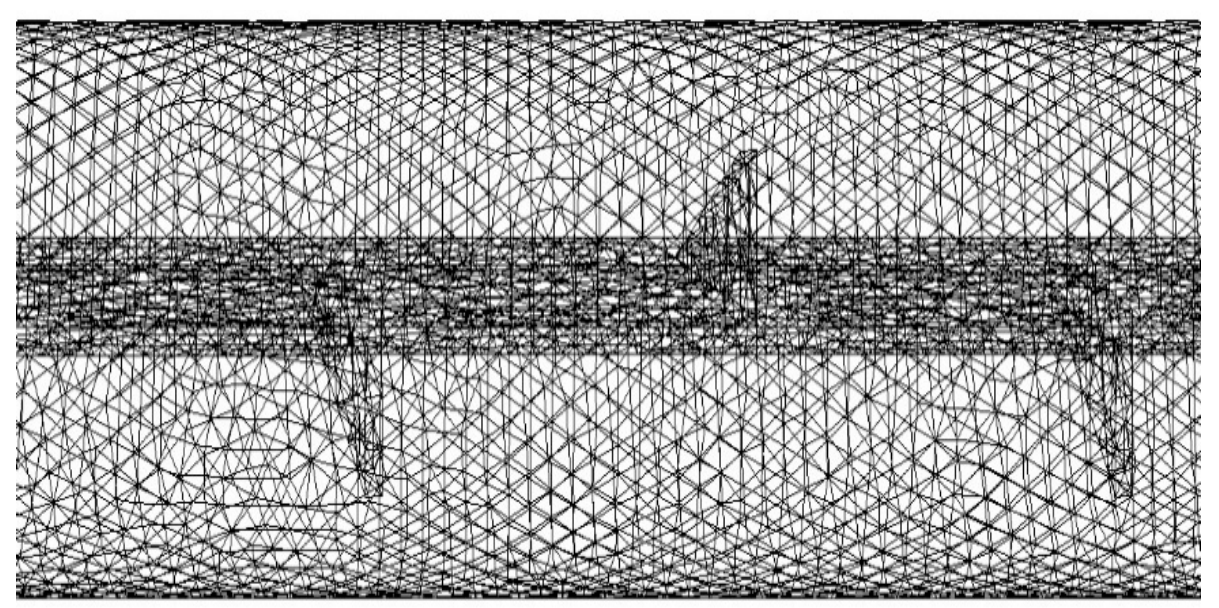

Figure 2. Grid generation. 


\section{Results and Discussion}

\subsection{Verification of the Numerical Results}

The grid system was designed using the tetrahedral grid type (see Figure 2). The face sizing was also performed in order to ensure that the grid is sufficiently dense and meets grid independence. The grid system was approximately 1,016,617 cells utilized to calculate the smooth-tube case. To verify the accuracy of the simulation result, the heat transfer, and fluid flow characteristics of the smooth-tube obtained from the current study were compared with the established correlations. The Nusselt number was compared by using the Petukhov and Gnielinski equations [24], while the friction factor was evaluated using the Blasius equation [25].

The Petukhov Nusselt number equation is

$$
N u=\frac{(f / 8) \operatorname{Re} \operatorname{Pr}}{1.07+12.7(f / 8)^{1 / 2}\left(\operatorname{Pr}^{2 / 3}-1\right)}
$$

for $10^{4}<\operatorname{Re}<5 \times 10^{6}$.

The Gnielinski equation is given by

$$
N u=\frac{(f / 8)(\operatorname{Re}-1000) \operatorname{Pr}}{1+12.7(f / 8)^{1 / 2}\left(\operatorname{Pr}^{2 / 3}-1\right)}
$$

for $1 \times 10^{3}<\operatorname{Re}<5 \times 10^{6}$.

The Blasius correlation used to predict the friction factor is given by

$$
f=0.3164 R e^{-0.25}
$$

for $4 \times 10^{3}<R e<1 \times 10^{5}$.

The Petukhov correlation for friction factor is

$$
f=(0.790 \ln \operatorname{Re}-1.64)^{-2}
$$

Figures 3 and 4 show a comparison of the Nusselt number and friction factor for the smooth tube with the established correlations, respectively. It was found that, for all cases, the difference between the present results with the established correlations were very limited. Hence, we can conclude that the results of the present simulation have reasonable accuracy. As compared to the established correlations, the differences between the Nusselt number of the present study and that of Petukhov and Gnilienski were $3.25 \%$ and $8.6 \%$, respectively. Furthermore, the difference in the friction factor was less than $5 \%$ as compared to the established correlation.

\subsection{Effect of Attack Angle on Heat Transfer Characteristic}

The tetrahedral grid was used for the meshing in the computations. To increase the accuracy of the simulation, the grid was highly converged in the insertion area. The generated grid can also be observed in Figure 2. A total of approximately 2,600,000 cells were used for the tube with PDWVGs. The influence of the PDWVGs on the heat transfer characteristics can be clearly observed in Figure 5, as compared to the smooth tube, the PDWGs result in a high Nusselt number $(\mathrm{Nu})$. The $\mathrm{Nu}$ is strongly affected by the temperature distribution of the fluid inside the enhanced tube. By maintaining the inlet conditions of the cold and hot fluid constant for all the cases, it is expected that turbulent flow generation will be apparent. 


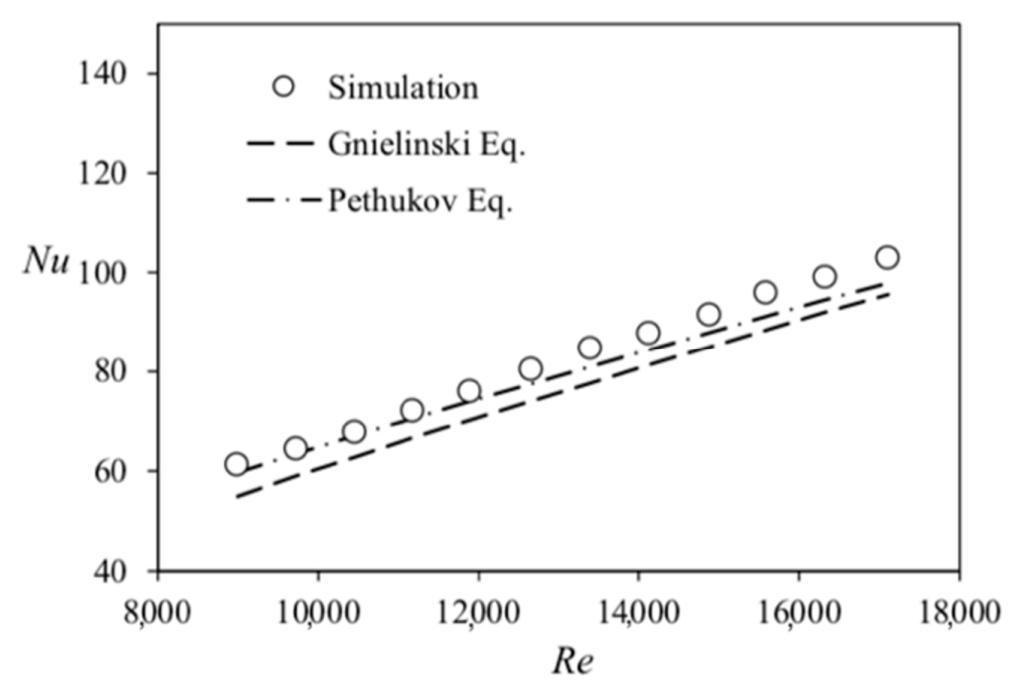

Figure 3. Nusselt number validation for plain tube.

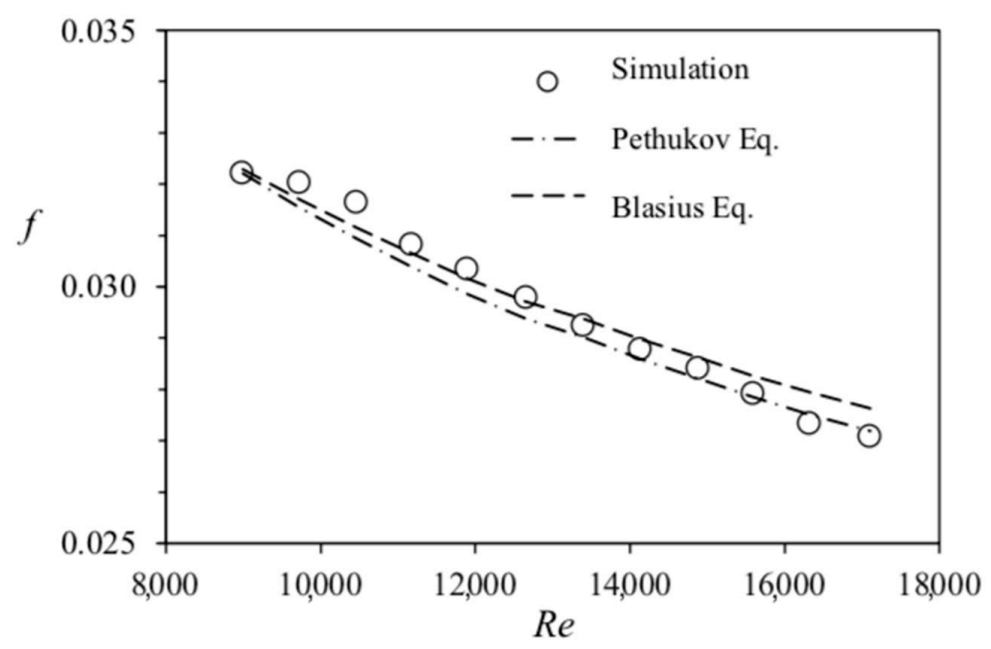

Figure 4. Friction factor validation for plain tube.

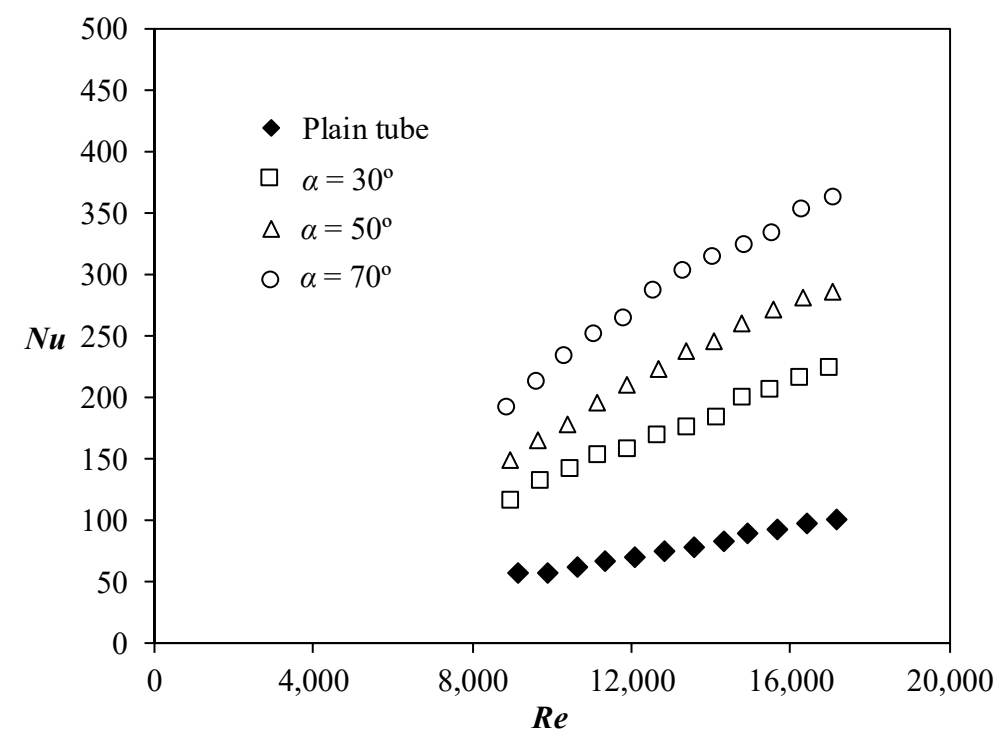

Figure 5. Nusselt number for various attack angles. 
Figure 6 shows a comparison of the temperature distribution of the smooth tube and the enhanced tube with PDWVGs at a Reynolds number $(R e)$ of 17,400 for various cross sections $(x / D)$. For the tube with PDWVGs, a better temperature distribution is obtained, which results in a better temperature gradient than that obtained with the smooth tube, as shown in Figure 6. It can be observed that for the tube with PDWVGs, for all variations, the temperature distribution can be more evenly spread. In addition, it can be observed that as the attack angle increases, the temperature distribution also follows a trend towards a homogeneous temperature distribution. The better temperature distribution results in a higher temperature difference between the inlet and outlet of the tube, which improves the convective heat transfer coefficient. Moreover, this phenomenon could also be explained using the streamline contour, as depicted in Figure 7. In the case of PDWVGs, with the increase in the attack angle, the vortex generation could grow more rapidly, which aids in improving the fluid mixing of the core fluid and the fluid near the wall. Moreover, as shown in Figure 7, as the attack angle increases, the main and corner vortex generation also increases, which could increase the flow velocity; as a consequence, the heat transfer rate could also be increased [26]. In addition, the development of vortices behind the wing structure aids in achieving a higher heat transfer rate. From the results, we found that the values of $\mathrm{Nu}$ are larger by $122 \%, 190 \%$, and $269 \%$ than those of the smooth tube for the attack angles of $30^{\circ}, 50^{\circ}$, and $70^{\circ}$, respectively.
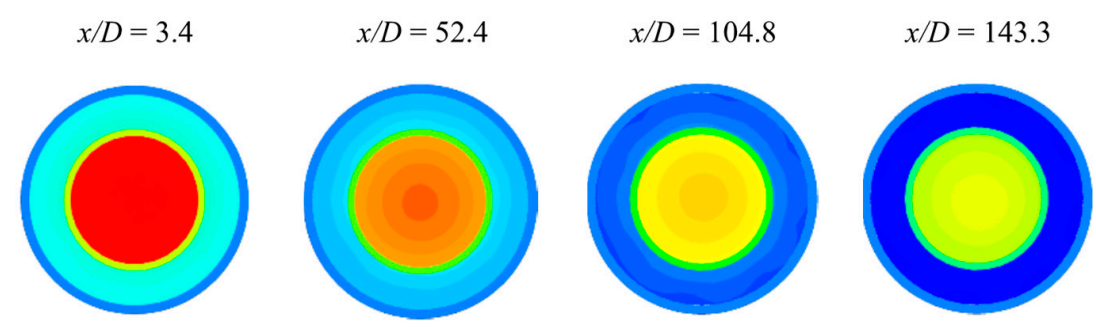

Plain tube
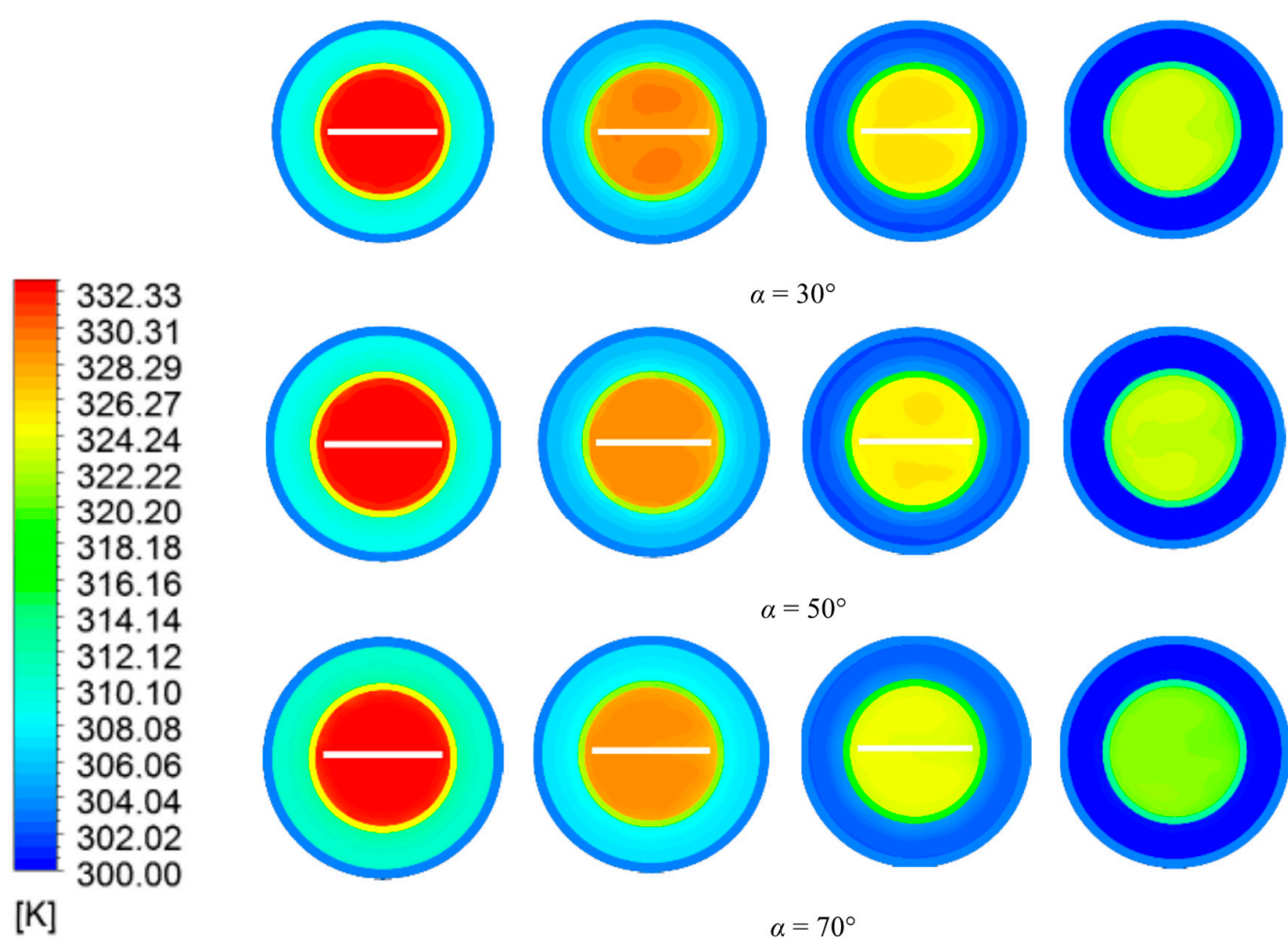

316.16

314.14

312.12

310.10

308.08

306.06

304.04

302.02

300.00

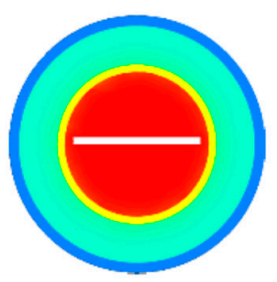

$\alpha=50^{\circ}$
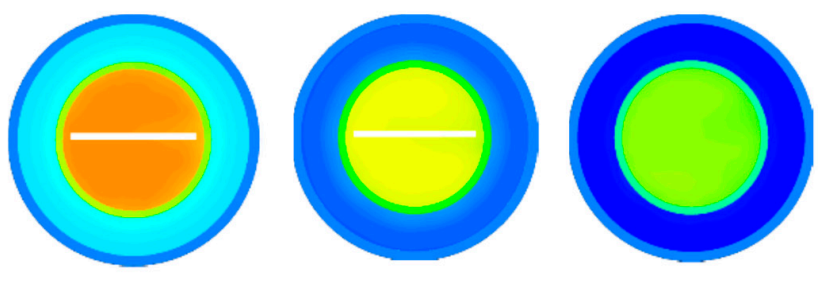

$\alpha=70^{\circ}$

Figure 6. Local inner tube temperature contour at $R e=17,400$. 


$$
x / D=3.4
$$

$$
x / D=52.4
$$

$$
x / D=104.8
$$

$$
x / D=143.3
$$
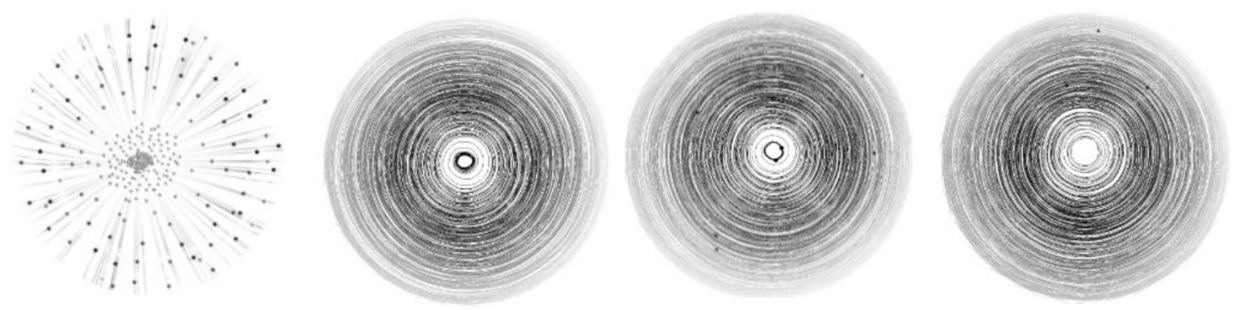

Plain tube
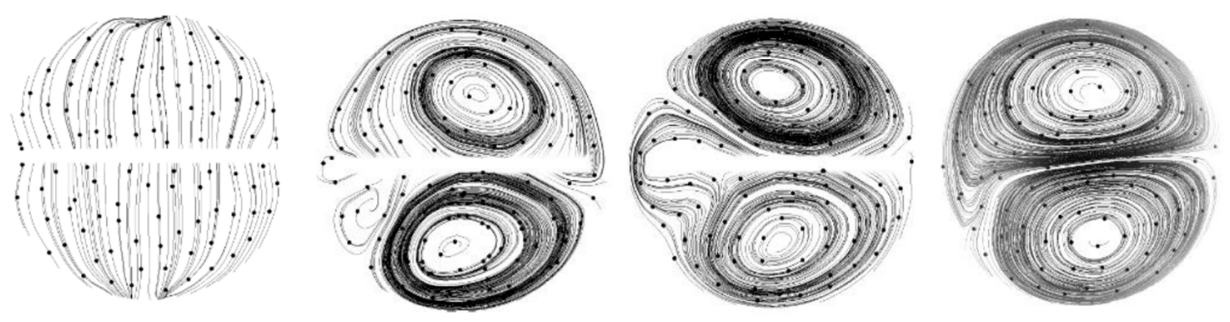

$\alpha=30^{\circ}$
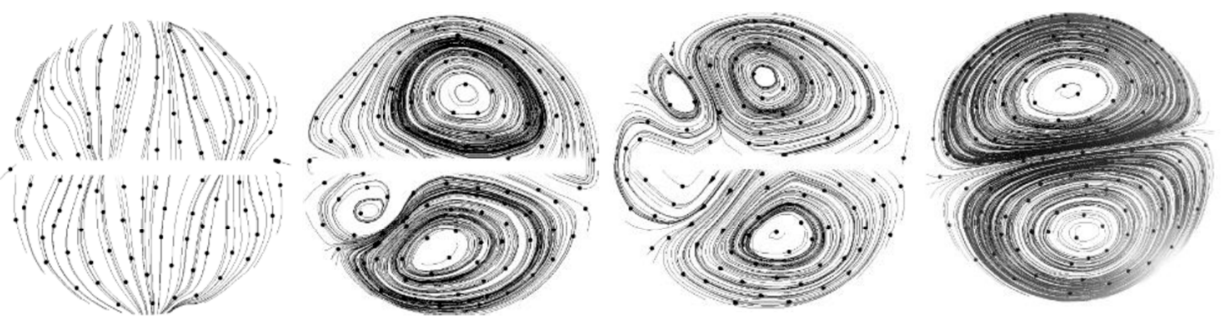

$\alpha=50^{\circ}$
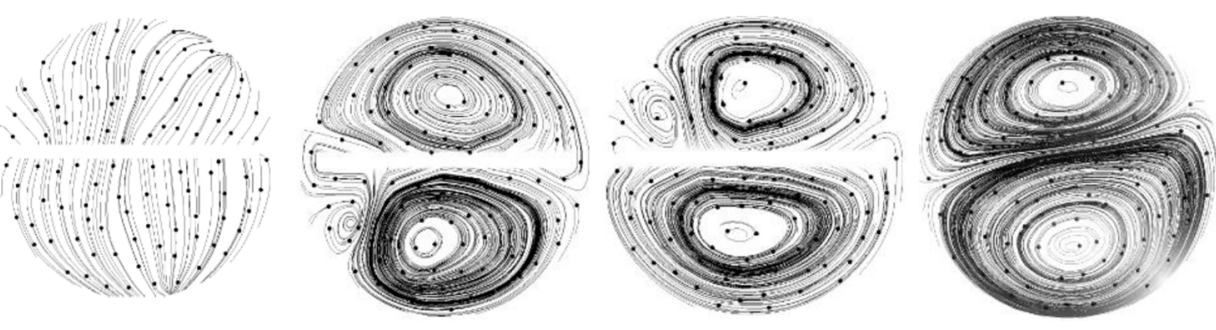

$\alpha=70^{\circ}$

Figure 7. Streamline in cross sections at $R e=17,400$.

\subsection{Effect of Attack Angle on Fluid Flow Characteristic}

Figure 8 shows the variations of the friction factors of the enhanced tubes as compared to the smooth tube. It can be observed that the tube with PDWVGs offers a higher friction factor than that of the smooth tube. Furthermore, the friction factor values also increase with the increase in the attack angle. This is because the presence of the PDWVGs provides a larger blockage area. This could also be explained using the velocity contour in Figure 9. Figure 9 shows the velocity contour of the smooth tube and the enhanced tube with PDWVGs at a Reynolds number $(R e)$ of 17,400 for various cross sections $(x / D)$. As observed in Figure 9, the velocity of the smooth tube is more uniform. While in the case of the tube with PDWVGs, it is observed that the existence of the PDWVGs causes a strong disturbance in the flow. Correspondingly, this increases the fluid friction near the wall, which increases the friction factor value. Moreover, from Figure 9, it can be clearly observed that for the highest attack angle, the velocity field is more highly intense than that in the case of a low attack angle, which means that the 
turbulence intensity is also high. It increases from the entrance to the exit of the tube. From the results, we observed that the friction factor of the PDWVGs is higher by approximately 7.09, 8.79, and 10.1 times that of the smooth tube for the attack angles of $30^{\circ}, 50^{\circ}$, and $70^{\circ}$, respectively. In addition, it is clear from Figures 6, 7, and 9 that numerical results provide a more in-depth understanding of the physical phenomenon of the heat transfer enhancement.

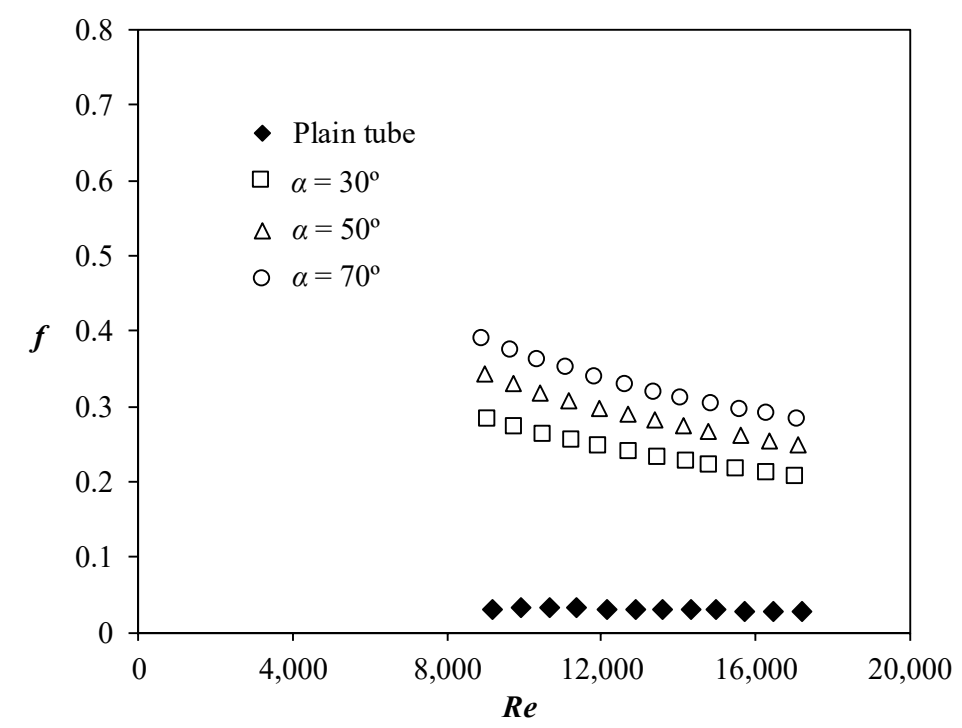

Figure 8. Friction factor for various attack angles.
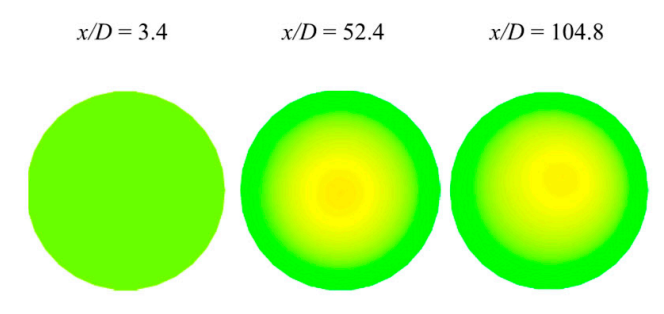

$x / D=143.3$
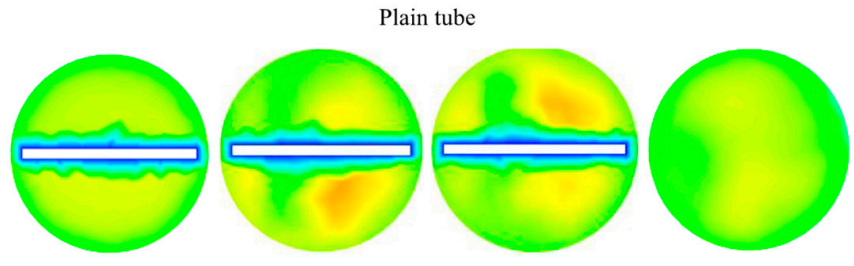

$\alpha=30^{\circ}$
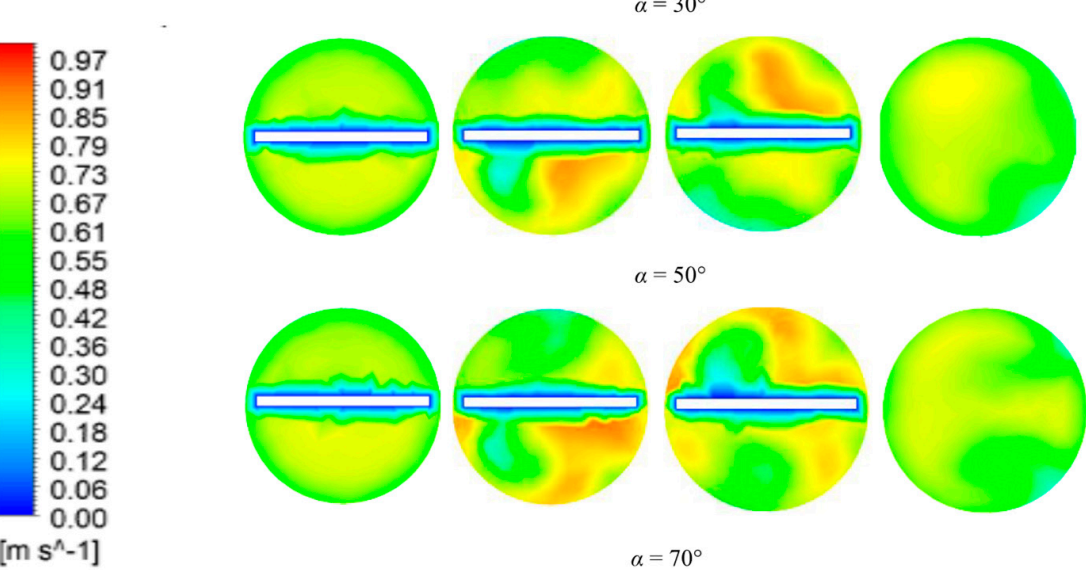

$\alpha=50^{\circ}$
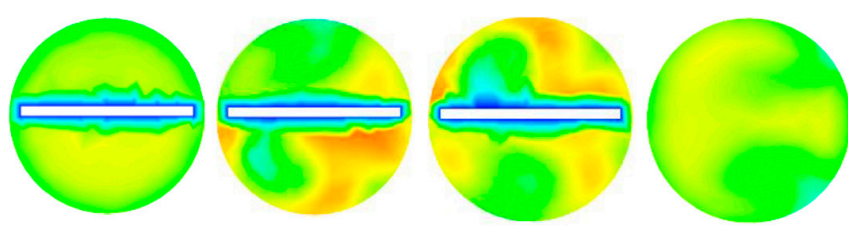

$\alpha=70^{\circ}$

Figure 9. Velocity contour at $\operatorname{Re}$ of 17,400. 


\subsection{Thermal Performance Factor}

The thermal performance of the enhanced tube heat exchanger is defined as the ratio of the heat transfer and friction factor characteristics of the enhanced tube to those of the basic device, which has a similar basic dimension without the design enhancement [27]. The equation for the thermal performance factor $(\eta)$ can be calculated as follows:

$$
\eta=\left.\frac{h_{t}}{h_{o}}\right|_{p p}=\left.\frac{N u_{t}}{N u_{o}}\right|_{p p}=\left(\frac{N u_{t}}{N u_{o}}\right)\left(\frac{f_{t}}{f_{o}}\right)^{-\frac{1}{3}}
$$

Figure 10 shows the thermal performance factor evaluation as a function of the Reynolds number. The numerical study was conducted under turbulent conditions with a high Reynolds number $(91,00-17,400)$. It is observed that for a low attack angle of $30^{\circ}$, the PDWVGs' performance was poor in turbulent region. However, for high attack angles of $50^{\circ}$ and $70^{\circ}$, the PDWVGs offer a superior performance by providing a high thermal performance factor. The average thermal performance factor was revealed to have a value of $1.1,1.01$, and 0.98 for the attack angles of $30^{\circ}, 50^{\circ}$, and $70^{\circ}$, respectively.

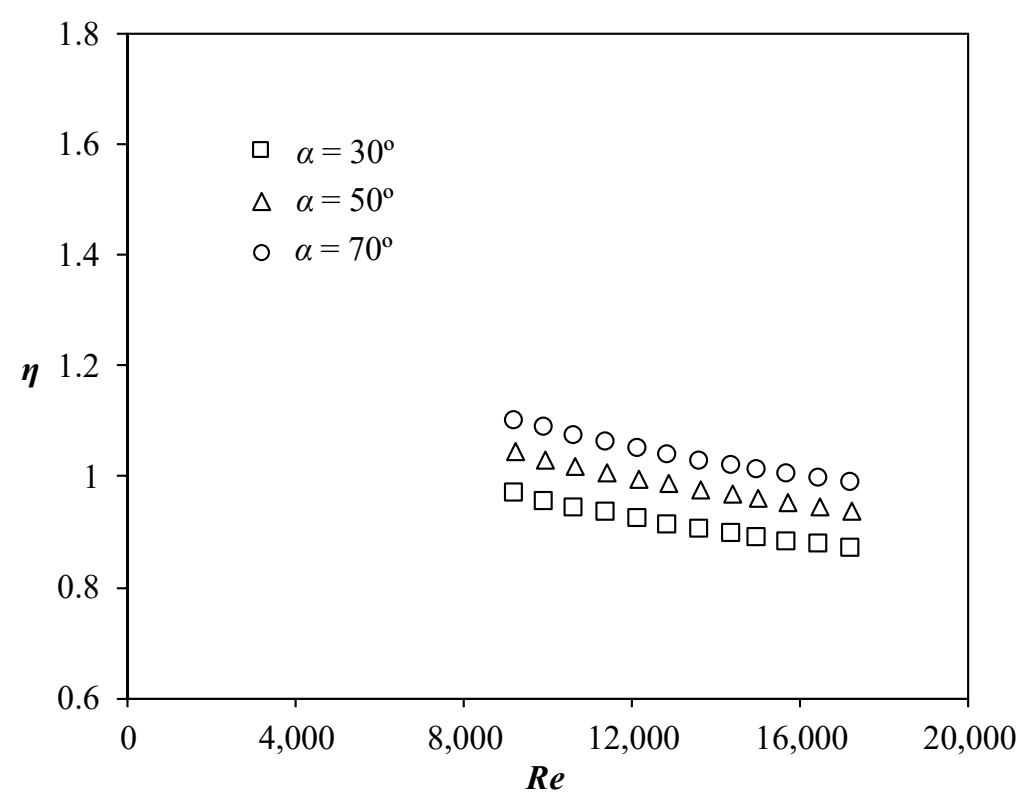

Figure 10. Thermal performance for various attack angles.

\subsection{Comparison of Obtained Results with the Experimental Results}

A comparative study was performed using the experimental results in [22]. Figures 11-13 show the comparison between the numerical and experimental study results. Benchmarking was conducted to observe the accuracy of the results obtained in the numerical study. The advantage of using a numerical study is that it can cover the velocity range that is possibly difficult to achieve using an experimental setup. The numerical study was focused on a high-turbulent flow, while the experimental study was focused on low-turbulent flow starting from the Reynold number of 5300 . It can be clearly observed that, for all the cases, there is no significant difference between the numerical and experimental study results. The numerical and experimental results obtained for the low Reynolds number region also matched well. From the figures, we can observe that the use of the PDWVGs provided an advantage even in the case of a high Reynolds number. As the Nusselt number increased, the friction factor decreased continuously in the range of $9100 \leq R e \leq 14,300$ (see Figures 11 and 12). This can be used as a guide towards achieving good system performance. 


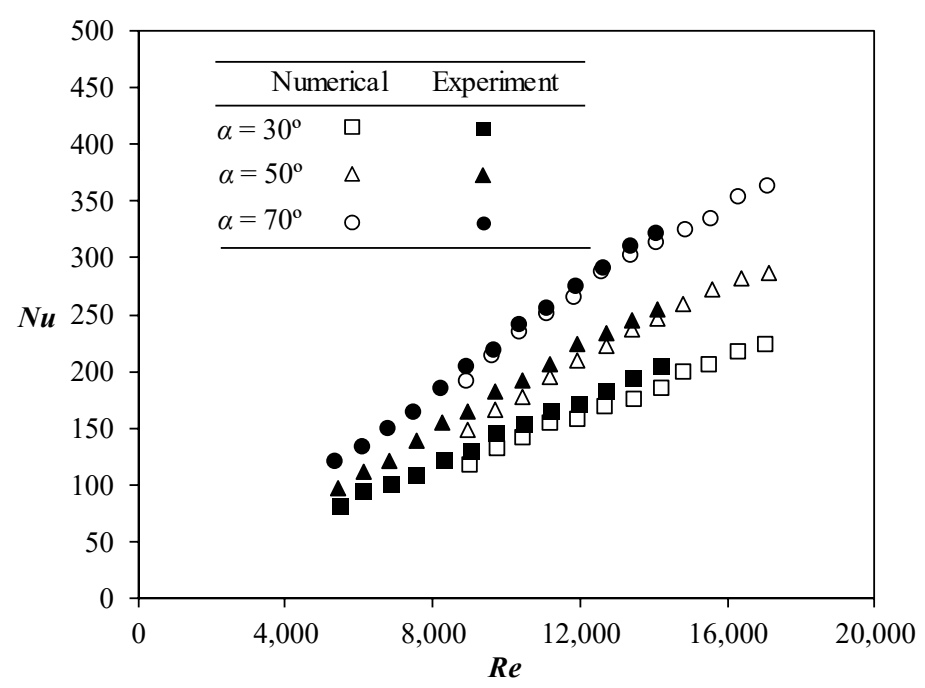

Figure 11. Nusselt number for numerical and experimental results.

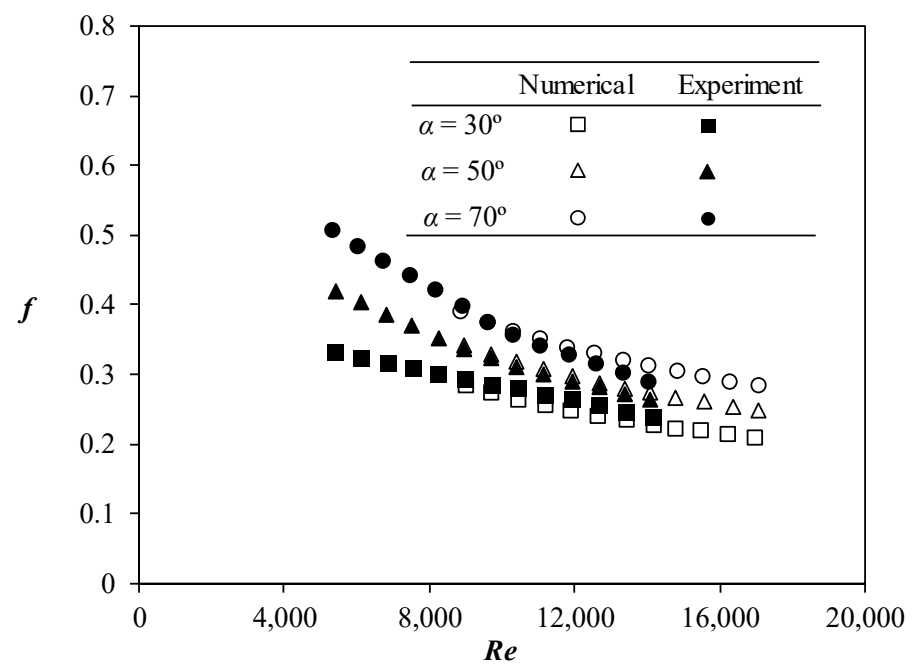

Figure 12. Friction for numerical and experimental results.

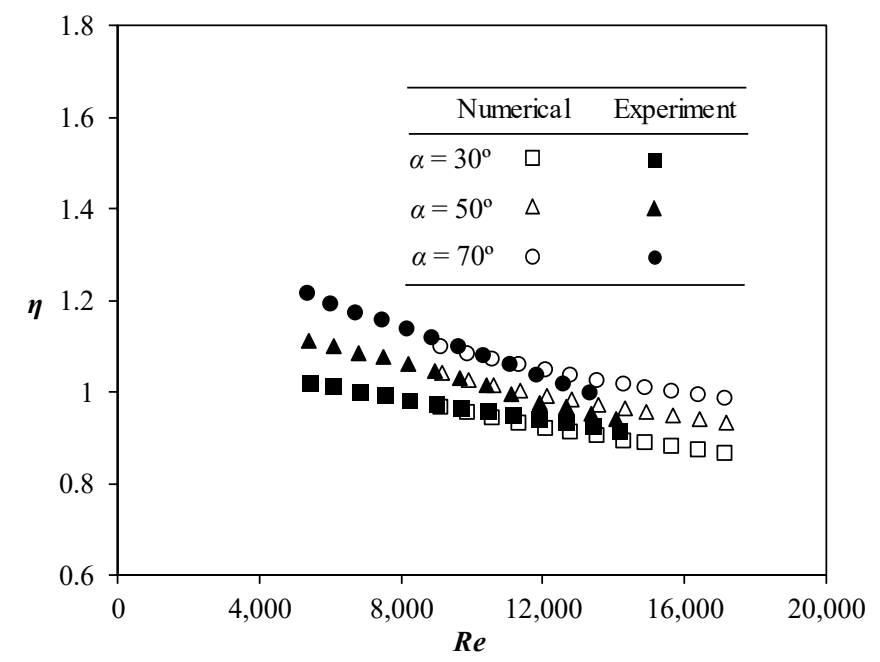

Figure 13. Thermal performance factor for numerical and experimental results. 


\section{Conclusions}

A numerical study of an enhanced tube with PDWVGs installed with various attack angles has been conducted. The following conclusions can be drawn:

- The Nusselt number $(\mathrm{Nu})$, friction factor $(f)$, and thermal performance factor $(\eta)$ of the PDWVGs with various attack angles are found to be higher than those of the smooth tube. As the attack angle increases, $N u, f$, and $\eta$ also increase.

- The highest increase in the Nusselt number and friction factor, respectively, was found to be up to $269 \%$ and 10.1 times higher than those of the smooth tube. These results have been sufficiently confirmed through experiments.

- It was revealed that the thermal performance factor approaches a value of 1.1.

- The heat transfer mechanism was clearly elucidated using the streamline and temperature distribution at the cross sections.

Author Contributions: A.T.W. conceived the main concept. A.T.W., M.A., and K.K. contributed to the investigation and data analysis. M.A. and A.M. contributed significantly to the supervised research. A.T.W. wrote the manuscript. All authors contributed in writing the final manuscript.

Funding: This research received no external funding to declare.

Acknowledgments: We are grateful to Universitas Sebelas Maret for funding this study. The partial financial assistance provided by Tokyo Institute of Technology is gratefully acknowledged. The authors wish to thank their former colleague, Dandy Anugerah Wicaksono, for his assistance during the data collection. The first author also wishes to acknowledge the Program of World Class Professor scheme B (2018) supported by the Ministry of Research, Technology and Higher Education of the Republic of Indonesia for the opportunity to have a research visit to Tokyo Institute of Technology, Japan during the revision of the manuscript.

Conflicts of Interest: The authors declare no conflict of interest.

\section{Nomenclature}

$c \quad$ chord length of the delta-wing [m]

$C_{p} \quad$ specific heat capacity at a constant pressure $[\mathrm{J} / \mathrm{kg} \cdot \mathrm{K}]$

$d \quad$ diameter of inner tube [m]

$D$ diameter of outer tube [m]

$f$ friction factor

$h$ average convective heat transfer coefficient of the plain tube $\left(\mathrm{W} / \mathrm{m}^{2} \cdot \mathrm{K}\right)$

$k \quad$ thermal conductivity $[\mathrm{W} / \mathrm{m} \cdot \mathrm{K}]$

$k_{\text {eff }}$ effective thermal conductivity $[\mathrm{W} / \mathrm{m} \cdot \mathrm{K}]$

$L \quad$ length of the inner tube $[\mathrm{m}]$

$\mathrm{Nu}$ average Nusselt number

$p \quad$ pitch of the delta-wing $[\mathrm{m}]$

Pr Prandtl number

Re Reynolds number

$t \quad$ thickness of the aluminum strip [m]

$T$ temperature [K]

$u \quad$ velocity of hot water in the inner tube $[\mathrm{m} / \mathrm{s}]$

$w \quad$ width of the delta-wing [m]

$W \quad$ width of the aluminum strip [m]

Greek symbols

$\alpha \quad$ angle of attack $\left[{ }^{\circ}\right]$

$\alpha P \quad$ pressure drop across the inner tube [Pa]

$\eta \quad$ thermal performance factor

$\mu \quad$ dynamic viscosity $[\mathrm{kg} / \mathrm{m} \cdot \mathrm{s}]$

$\rho$ density of hot water $\left[\mathrm{kg} / \mathrm{m}^{3}\right]$ 


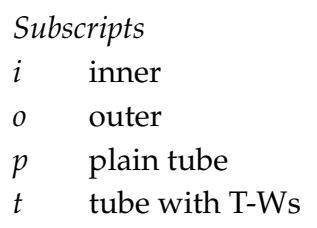

\section{References}

1. Honda, H.; Wijayanta, A.T.; Takata, N. Condensation of R407C in a horizontal microfin tube. Int. J. Refrig. 2005, 28, 203-211. [CrossRef]

2. Xue, Y.; Ge, Z.; Du, X.; Yang, L. On the heat transfer enhancement of plate fin heat exchanger. Energies 2018, 11, 1398. [CrossRef]

3. Ray, S.; Date, A.W. Friction and heat transfer characteristics of flow through square duct with twisted tape insert. Int. J. Heat Mass Transfer 2003, 46, 889-902. [CrossRef]

4. Yaningsih, I.; Wijayanta, A.T.; Miyazaki, T.; Koyama, S. V-cut twisted tape insert effect on heat transfer enhancement of single phase turbulent flow heat exchanger. AIP Conf. Proceed. 2018, 1931, 030038. [CrossRef]

5. Bellos, E.; Tzivanidis, C. Enhancing the performance of evacuated and non-evacuated parabolic trough collectors using twisted tape inserts, perforated plate inserts and internally finned absorber. Energies 2018, 11, 1129. [CrossRef]

6. Naphon, P.; Sriromruln, P. Single-phase heat transfer and pressure drop in the micro-fin tubes with coiled wire insert. Int. Commun. Heat Mass Transfer 2006, 33, 176-183. [CrossRef]

7. Jafari Nasr, M.R.; Khalaj, A.H.; Mozaffari, S.H. Modeling of heat transfer enhancement by wire coil inserts using artificial neural network analysis. Appl. Therm. Eng. 2010, 30, 143-151. [CrossRef]

8. Sivashanmugam, P.; Suresh, S. Experimental studies on heat transfer and friction factor characteristics of turbulent flow through a circular tube fitted with regularly spaced helicalscrew-tape inserts. Appl. Therm. Eng. 2017, 27, 1311-1319. [CrossRef]

9. Sadeghi, O.; Mohammed, H.A.; Bakhtiari-Nejad, M.; Wahid, M.A. Heat transfer and nanofluid flow characteristics through a circular tube fitted with helical tape inserts. Int. Commun. Heat Mass Transfer 2016, 71, 234-244. [CrossRef]

10. Hiravennavar, S.R.; Tulapurkara, E.G.; Biswas, G. A note on the flow and heat transfer enhancement in a channel with built-in winglet pair. Int. J. Heat Fluid Flow 2007, 28, 299-305. [CrossRef]

11. Yaningsih, I.; Wijayanta, A.T.; Miyazaki, T.; Koyama, S. Impact of blockage ratio on thermal performance of delta-winglet vortex generators. Appl. Sci. 2018, 8, 1-14. [CrossRef]

12. Wijayanta, A.T.; Yaningsih, I.; Aziz, M.; Miyazaki, T.; Koyama, S. Double-sided delta-wing tape inserts to enhance convective heat transfer and fluid flow characteristics of a double-pipe heat exchanger. Appl. Therm. Eng. 2018, 145, 27-37. [CrossRef]

13. Torii, K.; Yanagihara, I. The effects of longitudinal vortices on heat transfer of laminar boundary layers. JSME Int. J. Ser. II 1989, 32, 395-402. [CrossRef]

14. Fu, W.; Tseng, C. Enhancement of heat transfer for a tube with an inner tube insertion. Int. J. Heat Mass Transfer 1994, 37, 499-509. [CrossRef]

15. Chen, Y.; Fiebig, M.; Mitra, N.K. Heat transfer enhancement of a finned oval tube with punched longitudinal vortex generators in-line. Int. J. Heat Mass Transfer 1998, 41, 4151-4166. [CrossRef]

16. Zimparov, V. Prediction of friction factors and heat transfer coefficients for turbulent flow in corrugated tubes combined with twisted tape inserts. Part 2: Heat transfer coefficients. Int. J. Heat Mass Transfer 2004, 47, 385-393. [CrossRef]

17. Chu, P.; He, Y.L.; Lei, Y.G.; Tian, L.T.; Li, R. Three-dimensional numerical study on fin-and-oval-tube heat exchanger with longitudinal vortex generators. Appl. Therm. Eng. 2009, 29, 859-876. [CrossRef]

18. Hong, Y.; Deng, X.; Zhang, L. 3D numerical study on compound heat transfer enhancement of converging-diverging tubes equipped with twin twisted tapes. Chin. J. Chem. Eng. 2012, 20, 589-601. [CrossRef]

19. Sheikholeslami, M.; Ganji, D.D. Heat transfer enhancement in an air to water heat exchanger with discontinuous helical turbulators; experimental and numerical studies. Energy 2016, 116, 341-352. [CrossRef] 
20. Xu, Y.; Islam, M.D.; Kharoua, N. Numerical study of winglets vortex generator effects on thermal performance in a circular pipe. Int. J. Therm. Sci. 2017, 112, 304-317. [CrossRef]

21. Piroozfam, N.; Shafaghi, A.H.; Razavi, S.E. Numerical investigation of three methods for improving heat transfer in counter-flow heat exchangers. Int. J. Therm. Sci. 2018, 133, 230-239. [CrossRef]

22. Wijayanta, A.T.; Istanto, T.; Kariya, K.; Miyara, A. Heat transfer enhancement of internal flow by inserting punched delta winglet vortex generators with various attack angles. Exp. Therm. Fluid Sci. 2017, 87, 141-148. [CrossRef]

23. ANSYS Fluent 15.0: Theory Guide; Fluent Inc.: Canonsburg, PA, USA, 2010.

24. Cengel, Y.A.; Ghajar, A.J. Heat and Mass Transfer: Fundamentals and Applications, 5th ed.; McGraw-Hill: New York, NY, USA, 2014.

25. White, F.M. Fluid Mechanics, 7th ed.; McGraw-Hill: New York, NY, USA, 2011.

26. Junmei, W.; Tao, W. Numerical investigation and analysis of heat transfer enhancement in channel by longitudinal vortex based on field principle energy. Front Energy Power Eng. 2008, 2, 71-78.

27. Saha, S.K.; Tiwari, M.; Sundén, B.; Wu, Z. Advances in Heat Transfer Enhancement; Springer: Cham, Switzerland, 2016.

(C) 2018 by the authors. Licensee MDPI, Basel, Switzerland. This article is an open access article distributed under the terms and conditions of the Creative Commons Attribution (CC BY) license (http://creativecommons.org/licenses/by/4.0/). 